\title{
Protecting prisoners' autonomy with advance directives: ethical dilemmas and policy issues
}

\author{
Roberto Andorno • David M. Shaw • \\ Bernice Elger
}

Published online: 21 May 2014

(C) Springer Science+Business Media Dordrecht 2014

\begin{abstract}
Over the last decade, several European countries and the Council of Europe itself have strongly supported the use of advance directives as a means of protecting patients' autonomy, and adopted specific norms to regulate this matter. However, it remains unclear under which conditions those regulations should apply to people who are placed in correctional settings. The issue is becoming more significant due to the increasing numbers of inmates of old age or at risk of suffering from mental disorders, all of whom might benefit from using advance directives. At the same time, the closed nature of prisons and the disparate power relationships that characterise them mean that great caution must be exercised to prevent care being withdrawn or withheld from inmates who actually want to receive it. This paper explores the issue of prisoners' advance directives in the European context, starting with the position enshrined in international and European law that prisoners retain all their human rights, except the right to liberty, and are therefore entitled to selfdetermination regarding health care decisions.
\end{abstract}

Keywords Advance directives - Prison - Selfdetermination $\cdot$ Ageing $\cdot$ Mental incapacity

\footnotetext{
R. Andorno $(\square)$

School of Law, University of Zurich, Rämistrasse 74/65, 8001 Zurich, Switzerland

e-mail: roberto.andorno@uzh.ch

D. M. Shaw · B. Elger

Institute for Biomedical Ethics, University of Basel, Basel, Switzerland

e-mail: david.shaw@unibas.ch

B. Elger

e-mail: b.elger@unibas.ch
}

\section{A growing prison population with specific health care needs}

In many countries, the number of prisoners who are elderly and/or suffering from mental disorders is steadily growing (Aday and Krabill 2012). The current situation is expected to worsen over the next few decades posing a serious challenge to prison authorities, who have an obligation to provide adequate healthcare to inmates. From the perspective of international human rights law, it is clear that prisoners retain all their fundamental rights except the right to liberty, although such rights may be subject to certain restrictions that are unavoidable in a closed environment (UN Human Rights Committee 1992, para. 3; European Court of Human Rights 2004, para. 50). Prisoners also retain their entitlement to access to healthcare, as well as the right to decide autonomously whether to accept or refuse a given treatment. There is no reason to deny them this right simply because they are in a penal institution. The main aims of prisons are punishment, rehabilitation and deterrence. Punishment means the restriction of liberty, it does not mean to let inmates get or remain sick, or to deny them the rights enjoyed by all citizens regarding health care decisions. Interference with these latter rights can even amount to inhuman or degrading treatment or torture, a violation of article three of the European Convention on Human Rights (Council of Europe 1950; Elger 2008b).

In this context, advance directives have the potential to enhance the self-determination of elderly prisoners and those at higher risk of developing mental disorders. These directives are statements that people make about their wishes regarding future provision, withholding or withdrawal of particular treatments in the event that they become unable to make decisions at some point. Over the last decade, attention in Europe has increasingly focused on the positive role that 
advance directives can play in promoting and protecting patients' autonomy. A number of countries have passed specific laws to regulate this matter and to determine the conditions under which advance directives can be legally binding (Andorno et al. 2009; Negri 2011; Goffin 2012). In some countries, such as the UK and Germany, even before the adoption of specific laws on the matter, the jurisprudence had stressed the binding nature of anticipatory treatment refusals (Jox et al. 2008). The Council of Europe has also in recent years made important steps to encourage Member States to facilitate the use of advance directives (Andorno 2013, pp. 195-214).

However, it is still unclear to what extent the general rules governing advance directives apply to individuals in correctional settings. The existing norms on the matter remain silent in this regard. Given the naturally coercive environment in which prisoners are placed, the criteria for valid advance directives need to be specifically discussed. To this end, this paper first presents the scope of advance directives and the general conditions for their validity. Then, it emphasizes the principle of equivalence of health care, and finally discusses the elements that need to be specifically considered when assessing the validity of advance directives made by prisoners.

\section{Advance directives: a tool of self-determination}

In modern medical ethics and law it is firmly established that patients have the right to accept or refuse any medical treatment that they are offered. Respect for patients' autonomy is the foundation of the informed consent requirement, but also ensure that patients can reject treatment, even if this decision might lead to death.

However, a problem arises when patients have lost their decision-making capacity due to a condition that is not likely to be reversible (e.g. persistent vegetative state, coma, severe head injury, dementia, etc.). What criteria should be used to make a decision in these situations? What if family members disagree about which treatment should be provided? What if doctors and relatives have different views regarding which treatments are excessive or futile?

During the last few decades, policymakers and academics have drawn attention to the potential utility of advance directives in solving these dilemmas. Advance directives enable patients to declare in advance their preferences regarding the provision, withholding or withdrawal of specified medical treatments (a living will), or to empower a trusted individual to make such decisions on their behalf (durable power of attorney), or to combine both these options. Usually, advance directives take the form of a treatment refusal, not of a request for a specific therapy. Treatment requests are obviously not binding for health care professionals, but can nevertheless help them to determine what is in the best interests of the patient.

These statements can be regarded as a "logical extension of patient self-determination" (Stewart 2007, p. 39). If decisions regarding treatments can be made contemporaneously, there is no reason why they cannot be made with the intention that they will come into effect in the future, should the patient become incompetent. In other words, advance directives provide patients with a very concrete tool to continue exercising their autonomy even if they lose decision-making capacity. While the immediate justification of advance health care decisions is respect for patient autonomy, it can be argued that their ultimate rationale rests upon the principles of beneficence and nonmaleficence, as they can contribute to patients' good by enabling them to refuse treatments that they believe would be more harmful than helpful.

Advance directives have traditionally been conceived to contribute to the decision-making process in situations where patients have lost consciousness. However, they can also be used when future mental incapacity is foreseen or feared due to some genetic predisposition or when the initial symptoms of a mental illness (for instance, Alzheimer's disease) are already being experienced. In such situations, advance decisions may cover future medical treatments in general, or be specifically focused on mental health treatments. In this second case, they are called "psychiatric advance directives" (PAD). Unlike general advance directives, which are normally used to refuse medical interventions, PADs can also have a positive scope, giving prior consent to a particular future psychiatric treatment or measure. This enables those caring for patients with PADs to avoid the lengthy legal processes that are otherwise required in order to determine what a patient would have wanted (Thomas and Watson 1998; Scheyett et al. 2010).

As mentioned above, a number of European countries have passed specific laws to regulate advance directives, and to establish the conditions for their validity and execution. Among the conditions they consider essential are the following:

(a) The individual must have all the necessary information to make an advance decision, just as all patients must have sufficient information to provide informed consent in the normal clinical context. The Mental Capacity Act Code of Practice (UK Department for Constitutional Affairs 2007) says that those helping people make decisions must ask "Does the person have all the relevant information they need to make a particular decision?" (Section 3) In the context of advance directives, the question becomes "Did the person have all the necessary information when the 
directive was created?" Where circumstances change significantly and these changes were not anticipated at the time the directive was created (see (d) below), it will be clear in some cases that the person did not have sufficient information about the future circumstances for the directive to be applicable.

(b) The individual must have been competent to make the directive at the time it was made. The crucial issue is whether the person was able to understand the nature and scope of the specified treatments when he or she made the decision. This capacity does not need to be proved: every adult is presumed to have capacity, but this presumption can be rebutted by evidence to the contrary.

(c) The individual must have been free to make the decision, i.e. no coercion or undue influence was exerted upon him or her. In this regard, in a famous judgement issued in 1992, a British court stated that the advance refusal of blood transfusion by a woman who was severely injured in a car accident was invalid because her mother, who was a Jehovah's Witness, exerted undue pressure on her to make her refuse the treatment prior to her becoming unconscious (England and Wales Court of Appeal, Civil Division 1992).

(d) There are no serious reasons to believe that the patient would have a different view had he or she had adequate knowledge of the current circumstances. Basically, this requires the advance directive to have been intended to cover the situation that has arisen. This requirement can be found, in similar terms, in various European national laws. For instance, the new Article 372.2 of the Swiss Civil Code provides that "the physician must respect the patient's advance directives, unless (...) serious doubts can be raised as to whether they are the expression of the patient's free will or whether they are in conformity with the presumed will of the patient in the current situation"; the UK Mental Capacity Act of 2005 requires the absence of "reasonable grounds for believing that circumstances exist which the person did not anticipate and which would have affected his decision had he anticipated them" (Section 25.4.c); Article 1901a of the German Civil Code requires that the specifications in the advance directives should be "in accordance with the current living and treatment condition of the patient".

(e) The wishes formulated in the advance directives are not contrary to the law. For instance, a request for active euthanasia would be illegal in most countries. Similarly, basic or essential care (warmth, shelter, hygiene measures, and the offer of oral food and water) are excluded from the scope of advance directives as they are not considered "medical treatments" (See, for instance, UK Code of Practice for the Mental Capacity Act, Section 9.28; KleteckaPulker 2007, p. 82).

Furthermore, the Council of Europe has made significant efforts to raise awareness among Member States about the need to promote patient autonomy by means of advance directives (including both living wills and powers of attorney). The first important step in this regard was made in 1997 with the adoption of the European Convention on Human Rights and Biomedicine ("Oviedo Convention"), which explicitly recognizes the value of advance directives:

The previously expressed wishes relating to a medical intervention by a patient who is not, at the time of the intervention, in a state to express his or her wishes shall be taken into account (Article 9).

In 2009, the Council of Europe's Committee of Ministers adopted the Recommendation (2009) 11 on "continuing powers of attorney and advance directives for incapacity", which develops in more detail the formalities for making advance directives, with a particular focus on the possibility of appointing a health care proxy, which was absent from the Oviedo Convention. On 25 January 2012, the Parliamentary Assembly of the Council of Europe approved the Resolution 1859 (2012) on "Protecting human rights and dignity by taking into account previously expressed wishes of patients", which encourages Member States that have not yet done so to implement the European standards concerning continuing powers of attorney and advance directives for incapacity and to review any relevant legislation.

\section{The principle of equivalence of health care}

The idea that prisoners should enjoy a standard of healthcare that is equivalent to that provided in the wider community has been termed "the principle of equivalence". This principle is enshrined in several international human rights instruments, such as the United Nations (1990) Basic Principles for the Treatment of Prisoners, which states: "Prisoners shall have access to the health services available in the country without discrimination on the grounds of their legal situation" (Principle 9). At the European level, the Council of Europe (1998) recommendation concerning the ethical and organizational aspects of health care in prison provides that health care services should be provided "in conditions comparable to those enjoyed by the general public" (Article 10). In summary, the principle of equivalence embodies the idea that "the fact that people are in prison does not mean that they have any reduced 
right to appropriate health care" (Coyle 2007, p. 7). Since the state has deprived those individuals of their liberty, it should take on a special responsibility to ensure that they have access to adequate health care services (Elger 2008a, b, 2011).

However, it must be acknowledged that the ethical principles governing access to health care services cannot always operate in the context of a prison. The security objectives of correctional settings may enter into conflict with respect for patient autonomy as it is usually understood outside the prison walls. An example of this is the impossibility for prisoners to enjoy the benefit of a real free choice of a physician. Prisoners may refuse the care offered by the prison's doctor, and may sometimes be visited by an external doctor or, in some special circumstances, attend a consultation outside the prison, but they cannot undertake regular treatment from a doctor they would have chosen outside the prison (Niveau 2007). More importantly, especially in urgent cases, a detainee cannot just visit an emergency department him- or herself, but needs first to convince prison guards that the matter is sufficiently urgent to call the nurse or physician. However, beyond the inevitable restrictions that are inherent to the structure and scope of correctional settings, it is a requirement of human rights law and of the ethical principle of justice that prisoners are entitled to the same rights regarding healthcare decisions as are accorded to any other competent adult patient in the wider community.

\section{Advance directives in prison}

If the principle of equivalence is taken seriously, there is no reason to deny prisoners the right to create advance directives in order to ensure that their preferences regarding healthcare are respected. However, the specific circumstances of imprisonment must be taken into account when assessing the execution of advance directives created in prison, or which were made before imprisonment but which take effect in prison. Two situations must be clearly distinguished:

Advance directives made before imprisonment

Incarceration represents a dramatic change in any individual's life, and is likely to have a significant impact on his or her attitude towards life, death, and healthcare preferences. Therefore, there are serious reasons for arguing that advance directives made before imprisonment are no longer valid, although they could sometimes provide a useful indicator of individual preferences. As already mentioned, the information criterion for consent applies equally to the creation and enforcement of advance directives. This poses a particular problem for the use of pre-existing directives in prisons, for two reasons. First, many prisoners will never have anticipated their arrest, conviction and imprisonment, all of which constitute essential information that the prisoner lacked at the time of making the directive. The fundamental life change represented by imprisonment would appear to render many such directives invalid. For example, in the UK, the Mental Capacity Act Code of Practice states that "To be applicable, an advance decision must apply to the situation in question and in the current circumstances" (Section 9.41). However, it is questionable whether any directive made without the knowledge that imprisonment would occur could meet this criterion. More generally, "It remains unclear whether a person who has never been imprisoned at all, or even prisoners who have not been incarcerated in a particular facility, would ever be able to evaluate correctly in advance how they would feel in that particular future situation." (Elger 2014).

In any case, it would be advisable that the individual entering into prison either confirms or modifies any previous healthcare instructions in order to adapt them to the new circumstances. Theoretically, it would be different if the person had foreseen future imprisonment in the advance directive and included explicit instructions relating to healthcare in prison, inasmuch as he or she was able to correctly judge in advance the living conditions in a correctional setting. But in practice it is very unlikely that the possibility of a future imprisonment would be mentioned in a directive, not least for the reason that such sensitive information could be shared and lead to stigmatization of the individual (Elger 2014).

\section{Advance directives made during imprisonment}

As in the general population, the great majority of people entering prison are not likely to have an advance directive. Therefore, health care professionals will be normally confronted with instructions made during imprisonment when assessing whether a given advance directive meets the criteria for validity in a penal institutions.

Among the five conditions mentioned above for the validity of advance directives, two are particularly important in the case of patient-prisoners: their competence at the time the directive was made, and their freedom from any form of coercion or deception.

\section{Competence}

It is well known that imprisonment can have a damaging effect on mental health, particularly in the case of long term sentences (WHO-ICRC 2006). From a global perspective, it has been reported that at least half of the nine 
million people detained in penal institutions around the world suffer from personality disorders, and one million prisoners or more worldwide suffer from serious mental disorders such as psychosis or depression (Blaauw and Marle 2007, p. 133). This is why special care must be taken when assessing whether inmates have the necessary decision-making capacity to give healthcare instructions in advance. This point is crucial because new advance directives cannot be created by individuals who are already incapable of giving valid consent; in such cases consent or refusal must be obtained from a person authorized to make decisions on behalf of the patient, taking into account his or her best interests.

The initial assumption must be that inmates are competent and that they are therefore able to give instructions about their future health care. The fact that the proportion of people suffering from mental disorders is higher in prison than among the general population is not a sufficient reason for denying them decision-making capacity. However, the increased prevalence of psychiatric disease in prisons does mean that prison physicians must be particularly careful when examining the competence of each individual (Elger 2014).

In addition, it should be noticed that mental capacity is not a matter of all or nothing; there are degrees of competence. Prisoners with a particular mental disorder and those suffering from senility are not automatically excluded from giving valid informed consent to a medical treatment. The individual's capacity should be assessed specifically on a case by case basis rather than by making inferences from the general features implied by a particular diagnosis (Van Staden and Krüger 2003). Thus, the crucial issue is whether inmates (even if mentally ill) still have the ability to understand, deliberate upon, and reach conclusions regarding healthcare, and to express their wishes about possible treatments. The prison physician plays a key role in the assessment of prisoners' competence.

A specific dilemma posed by a person with incapacitating mental illness is what to do if, at the time of the execution of the instructions, the current wishes of the mentally incompetent individual contradict those expressed in his or her directive. This issue becomes particularly dramatic in the case of life-sustaining treatments that that the individual would like to continue, but which were rejected in the advance directive. Ronald Dworkin solves this dilemma by giving priority to so-called "precedent autonomy", which means that the current wishes of the incompetent patient can be simply ignored. He grounds this conclusion by prioritizing what he calls a person's "critical interests", or meaningful life goals and projects, over "experiential interests", or desires to have enjoyable experiences, even if the person has become unaware of her critical interests (1994, p. 226). Rebecca Dresser has levelled a number of objections against Dworkin's theory. For instance, she claims that the authors of an advance refusal of treatment may be unaware of the threat to their future welfare if the directive is implemented: "people may be mistaken about their future experiential interests as incompetent individuals". This is one of the reasons why, in her view, autonomy should not have primacy over the duty to protect the welfare of incompetent patients and to treat them with compassion (Dresser 1995). Similarly, it has been argued that "if a patient is still enjoying life or is showing a clear will to live, it would be unthinkable to implement the advance directive according to this current/ future best interests-standard" (Lemmens 2012, p. 183) and that "there can be cases in medical practice (...) in which it is justified to violate the mandate of autonomy in favour of the well-being of the dementia patient" (Vollmann 2001). Likewise, the German Ethics Council has stated that an advance refusal cannot be implemented if the incompetent patient clearly shows a "will to live" (Lebenswillen). In this regard, all forms of expression of such a will to live, including non-verbal ones, have to be taken into account. (2012, p. 89).

\section{Freedom}

The second crucial criterion that must be met for an advance directive to be valid is that its author was free from any form of coercion or deception at the time the directive was made. This criterion guarantees the voluntariness of any decisions documented in the directive. This condition is not to be taken for granted in a correctional setting. The disparate power relationships and the closed nature of the prison environment do not facilitate the exercise of prisoners' autonomy regarding health care. Inmates are accustomed to simply following orders, to conforming to the rules of the institution, and to avoid taking the initiative on virtually any relevant issue. In this context, it is not only difficult for them to make autonomous decisions about health care, but also challenging to even be aware that they have a right to accept or reject treatment. The simple fact that prison guards are the gatekeepers of health services means that in countries where the principle of equivalence as well as the independence of health care professionals and confidentiality are not respected, it is often very difficult or impossible to distinguish between refusal of care and denial of care (Dubler 1998).

The risk of coercion by prison staff must be taken into account when assessing the validity of advance directives made in prison. Prison authorities may be tempted to put pressure on prisoners to make them refuse treatment, either for budgetary reasons, or in order to exonerate the penal institution from any responsibility in case fragile inmates 
die as a result of inadequate health care. As Thomas and Watson (1998) point out, the use of advance directives in penal settings can enable inmates to exercise their autonomy regarding treatment, but also introduces the potential for yet another form of coercion against prisoners, particularly those who are more vulnerable. The danger is that advance directives could be misused by prison authorities to deny care to prisoners who have not chosen to reject it (Dubler 1998).

Another risk is that prison staff may exert pressure on inmates to accept medical treatments that they sincerely do not want. This coercion could be motivated by the desire to prevent any suspicion that prisoners did not receive equivalent healthcare, especially if death may result from a lack of treatment. It must be remembered that the European Court of Human Rights has repeatedly declared that the lack of appropriate health care for sick prisoners is a form of inhuman or degrading treatment, which is condemned by Article 3 of the European Convention on Human Rights (European Court of Human Rights. Press Unit 2012).

Another difficult dilemma relates to the intention that may lead prisoners to reject medical treatments. What if the prisoner's refusal (particularly in the case of life-threatening problems) is not motivated by the rejection of the treatment itself, but is the result of a depressive state of mind caused by poor living conditions in prison? What if the prospect of remaining in prison for many years leads them to reject any future medical intervention in order to die as soon as possible? In such situations, a delicate balance is to be struck between the duty of prison authorities to respect inmates' health care preferences and the equally important duty to prevent suicides among prisoners.

But how can it be established whether the main motivation for treatment refusal are the poor living conditions in prison? How to determine whether the inmate would have accepted the proposed treatment if he or she were outside the penal institution? Once again, the independence and professional skills of the prison physician are crucial here. Doctors are called to engage an open dialogue with prisoners at the time they make an advance directive, explaining them the different treatments, exploring their real preferences regarding future medical interventions in case of future incapacity, and evaluating the authenticity of their wishes. If the doctor comes to the conclusion that the advance refusal of care is genuine, he or she should respect the directive once the time to use it arrives. However, if the doctor believes sincerely that the treatment refusal is mainly motivated by a wish to die in order to "escape" from prison, and not by a rejection of the treatment itself, then he or she would probably need to adopt a more proactive approach. In such situations, the role of physicians should be to dissuade prisoners from misusing the tool of advance directives for committing suicide, and trying to help them to overcome the depression. In the case of prisoners diagnosed with short term fatal diseases, authorities are obliged to examine the possibility of humanitarian release or pardon, which would permit detainees to die with dignity outside of the prison context (Council of Europe 1998, para. 51).

The independence of prison physicians from prison authorities is essential to prevent a misuse of advance directives and to determine whether prisoners' instructions are genuine, and not the result of any form of pressure or manipulation by the prison staff. This can be facilitated by establishing close links between prison physicians and public health authorities, and by transferring prison health services to the general health services of the country and making them independent from the government agency responsible for the prisons. In France, for instance, legislation was introduced in 1994 placing prison health under the General Health Directorate for public health issues in the Ministry of Health. In England and Wales, the responsibility and also the budget for prison health care was transferred to the National Health Service in 2002 (Coyle 2007, p. 9).

\section{Conclusion}

Prisoners have a right to a standard of medical care which is equivalent to that provided in the wider community. They also retain their entitlement to autonomy regarding health care decisions. If these principles are taken seriously, then there are a priori no reasons why prisoners should not benefit from the possibility of making health care decisions in advance.

Over the last decade, many European institutions have given a strong impetus to the use of advance directives, either in the form of living wills, of continuing powers of attorney, or of a combination of both. We have clarified the circumstances in which the use of advance directives is appropriate in the context of prisons and prisoners. The three most important elements to consider are the quality and relevance of the information provided, the mental competence of the prisoner, and his or her freedom from any form of coercion or deception at the time the directive was made.

While advance directives can play a positive role in enabling prisoners to continue exercising their autonomy once they lose decision-making capacity, they can also provide an opportunity for abuse of the most vulnerable inmates. Great care must be exercised to guarantee that prisoners are mentally competent at the time they give their instructions, and that they are free to express their genuine wishes. 


\section{References}

Aday, R., and J. Krabill. 2012. Older and geriatric offenders: Critical issues for the 21st Century. In Special needs offenders in correctional institutions, ed. L. Gideon, 203-232. Los Angeles: Sage Publications.

Andorno, R., N. Biller-Andorno, and S. Brauer. 2009. Advance health care directives: Towards a coordinated European policy? European Journal of Health Law 16(3): 207-227.

Andorno, R. 2013. Principles of international biolaw. Seeking common ground at the intersection of bioethics and human rights. Brussels: Bruylant.

Blaauw, E., and H. van Marle. 2007. Mental health in prisons. In Health in prisons: A WHO guide to the essentials in prison health, ed. L. Møller, H. Stöver, R. Jürgens, A. Gatherer, and H. Nikogosian, 133-145. Copenhagen: WHO Regional Office for Europe.

Council of Europe. 1950. Convention for the Protection of Human Rights and Fundamental Freedoms. Rome, 4 November 1950. http:// www.echr.coe.int/Documents/Convention_ENG.pdf. Accessed 15 Feb 2014

Council of Europe. 1998. Recommendation (98)7of 8 April 1998 concerning the ethical and organizational aspects of health care in prison. http://legislationline.org/documents/action/popup/id/ 8069. Accessed 15 Feb 2014.

Council of Europe. Committee of Ministers. 2009. Recommendation (2009)11 of 9 December 2009 on continuing powers of attorney and advance directives for incapacity. https://wcd.coe.int/View Doc.jsp?id=1563397\&Site=CM. Accessed 15 Feb 2014.

Council of Europe. Parliamentary Assembly. 2012. Resolution 1859 (2012) of 25 January 2012 concerning "Protecting human rights and dignity by taking into account previously expressed wishes of patients". http://assembly.coe.int/Main.asp?link=/Documents/ AdoptedText/ta12/ERES1859.htm. Accessed 15 Feb 2014.

Coyle, A. 2007. Standards in prison health: the prisoner as a patient. In Health in prisons: $A$ WHO guide to the essentials in prison health, ed. L. Møller, H. Stöver, R. Jürgens, A. Gatherer, and H. Nikogosian, 7-14. Copenhagen: WHO Regional Office for Europe.

Dresser, R. 1995. Dworkin on dementia: elegant theory, questionable policy. Hastings Center Report 25(6): 32-38.

Dubler, N. 1998. The collision of confinement and care: End-of-life care in prisons and jails. Journal of Law, Medicine and Ethics 26(2): 149-156.

Dworkin, R. 1994. Life's Dominion. An Argument About Abortion, Euthanasia, and Individual Freedom. New York: Vintage.

England and Wales Court of Appeal. Civil Division. 1992. Re T. (Adult: Refusal of Treatment). All Engl Law Rep 30(4): 649-670.

Elger, B. 2008a. Medical ethics in correctional healthcare: An international comparison of guidelines. Journal of Clinical Ethics 19(3): 234-248. discussion 254-259.

Elger, B. 2008b. Towards equivalent health care of prisoners: European soft law and public health policy in Geneva. Journal of Public Health Policy 29(2): 192-206.

Elger, B. 2011. Prison medicine, public health policy and ethics: The Geneva experience. Swiss Medical Weekly 141: w13273. doi:10. 4414/smw.2011.13273.

Elger, B. 2014. Advance directives in the context of imprisonment. In Advance directives, ed. N. Biller-Andorno, S. Brauer, and P. Lack, 101-118. Berlin: Springer.
European Court of Human Rights. 2004. Gelfmann v. France, no 25875/03, judgment of 13 December 2004.

European Court of Human Rights. Press Unit. 2012. Factsheet: Prisoners Health Rights. http://www.echr.coe.int/ECHR/en/ Header/Press/Information+sheets/Factsheets/. Accessed 15 Feb 2014.

German Ethics Council. 2012. Dementia and self-determination. Opinion (orig. title: Demenz und Selbstbestimmung. Stellungnahme). 24 April 2012. http://www.ethikrat.org/publica tions/opinions/dementia-and-self-determination. Accessed 15 Feb 2014.

Goffin, T. 2012. Advance directives as an instrument in an ageing Europe. European Journal of Health Law 19(2): 121-140.

Jox, R., S. Michalowski, J. Lorenz, and J. Schildmann. 2008. Substitute decision making in medicine: Comparative analysis of the ethico-legal discourse in England and Germany. Medicine, Health Care and Philosophy 11(2): 153-163.

Kletecka-Pulker, M. 2007. Grundzüge und Zielsetzungen des Patientenverfügungs-Gesetzes. In Das österreichische Patientenverfügungsgesetz. Ethische und rechtliche Aspekte, ed. U. Körtner, C. Kopetzki, and M. Kletecka-Pulker, 81-96. Vienna: Springer.

Lemmens, C. 2012. End-of-life decisions and demented patients. What to do if patient's current and past wishes are in conflict with each other? European Journal of Health Law 19(2): 177-186.

Negri, S. (ed.). 2011. Life, death and dignity. Regulating advance directives in national and international law. Leiden: Brill Academic Publishers.

Niveau, G. 2007. Relevance and limits of the principle of 'equivalence of care' in prison medicine. Journal of Medical Ethics 33(10): 610-613.

Scheyett, A., J. Vaughn, and A. Francis. 2010. Jail administrators' perceptions of the use of psychiatric advance directives in jails. Psychiatric Services 61(4): 409-411.

Stewart, C. 2007. Advance directives: Disputes and dilemmas. In Disputes and dilemmas in health law, ed. I. Freckelton, and K. Petersen, 38-53. Sidney: Federation Press.

Thomas, D.L., and J.M. Watson. 1998. Advance directives in a correctional setting. Psychology, Public Policy, and Law 4(3): 878-900.

UK Department for Constitutional Affairs. 2007. MCA Code of Practice. http://www.dca.gov.uk/legal-policy/mental-capacity/ mca-cp.pdf. Accessed 15 Feb 2014.

UN Human Rights Committee. 1992. CCPR General Comment No. 21: Article 10 (Humane Treatment of Persons Deprived of Their Liberty), 10 April 1992. http://www.unhcr.org/refworld/docid/ 453883fb11.html. Accessed 15 Feb 2014.

UN General Assembly. 1990. Basic Principles for the Treatment of Prisoners. Resolution 45/111 of 14 December 1990. http://www. un.org/documents/ga/res/45/a45r111.htm. Accessed 15 Feb 2014.

Van Staden, C.W., and C. Krüger. 2003. Incapacity to give informed consent owing to mental disorder. Journal of Medical Ethics 29: $41-43$.

Vollmann, J. 2001. Advance directives in patients with Alzheimer's disease. Medicine, Health Care and Philosophy 4(2): 161-167.

WHO-ICRC (World Health Organization and International Committee of the Red Cross). 2006. Mental health and prisons. Information sheet. Geneva. http://www.who.int/mental_health/ policy/mh_in_prison.pdf. Accessed 15 Feb 2014. 